\title{
Sputum mast cell subtypes relate to eosinophilia and corticosteroid response in asthma
}

\author{
Gang Wang ${ }^{1,2}$, Katherine J. Baines ${ }^{2}$, Juan Juan Fu', Lisa G. Wood ${ }^{2}$, \\ Jodie L. Simpson ${ }^{2}$, Vanessa M. McDonald ${ }^{2}$, Douglas C. Cowan ${ }^{3}$, \\ D. Robin Taylor ${ }^{3}$, Jan O. Cowan ${ }^{3}$ and Peter G. Gibson ${ }^{1,2}$
}

Affiliations: ${ }^{1}$ Pneumology Group, Dept of Integrated Traditional Chinese and Western Medicine, West China Hospital, Sichuan University, and Collaborative Innovation Center for Biotherapy, Chengdu, P.R. China. ${ }^{2}$ Center for Asthma and Respiratory Diseases, Dept of Respiratory and Sleep Medicine, John Hunter Hospital, Hunter Medical Research Institute, University of Newcastle, New Lambton, NSW, Australia. ${ }^{3}$ The Dunedin School of Medicine, University of Otago, Dunedin, New Zealand.

Correspondence: Katherine J. Baines, Level 2, West Wing, Hunter Medical Research Institute, Lot 1 Kookaburra Circuit, New Lambton Heights, NSW 2305, Australia. E-mail: Katherine.bainesवnewcastle.edu.au

ABSTRACT Mast cells are a resident inflammatory cell of the airways, involved in both the innate and adaptive immune response. The relationship between mast cells and inflammatory phenotypes and treatment response of asthma is not clear.

Clinical characteristics of subjects with stable asthma $(n=55)$, inflammatory cell counts and gene expression microarrays in induced sputum were analysed. Sputum mast cell subtypes were determined by molecular phenotyping based on expression of mast cell biomarkers (tryptase (TPSAB1), chymase (CMA1) and carboxypeptidase A3 (CPA3)). Effects of mast cell subtypes on steroid response were observed in a prospective cohort study $(\mathrm{n}=50)$.

$\mathrm{MC}_{\mathrm{T}}(\mathrm{n}=18)$ and $\mathrm{MC}_{\mathrm{T} / \mathrm{CPA} 3}$ (mRNA expression of TPSAB1 and CPA3; $\left.\mathrm{n}=29\right)$ subtypes were identified, as well as a group without mast cell gene expression $(n=8)$. The $\mathrm{MC}_{\mathrm{T} / \mathrm{CPA} 3}$ subtype had elevated exhaled nitric oxide fraction, sputum eosinophils, bronchial sensitivity and reactivity, and poorer asthma control. This was accompanied by upregulation of 13 genes. Multivariable logistic regression identified CPA3 (OR 1.21, p=0.004) rather than TPSAB1 (OR 0.92, $\mathrm{p}=0.502$ ) as a determinant of eosinophilic asthma. The $\mathrm{MC}_{\mathrm{T} / \mathrm{CPA} 3}$ subtype had a better clinical response and reduced signature gene expression with corticosteroid treatment.

Sputum mast cell subtypes of asthma can be defined by a molecular phenotyping approach. The $\mathrm{MC}_{\mathrm{T} / \mathrm{CPA} 3}$ subtype demonstrated increased bronchial sensitivity and reactivity, and signature gene expression, which was associated with airway eosinophilia and greater corticosteroid responsiveness.

@ERSpublications

Mast cell subtypes detected in sputum relate to eosinophilic inflammation and treatment responsiveness in asthma http://ow.ly/UsEIE

For editorial comment see Eur Respir J 2016; 47: 1040-1042 [DOI: 10.1183/13993003.00065-2016].

This article has supplementary material available from erj.ersjournals.com

Received: Aug 062015 | Accepted after revision: Oct 312015 | First published online: Dec 232015

Support statement: This study was partly supported by National Natural Science Foundation of China (81241002 and 81370122), Sichuan Youth Science and Technology Foundation (2010JQ0008), Youth Science Funding of Sichuan University (2011SCU04B17) and Program for New Century Excellent Talents in University, China (NCET-12-0380), and by the Hunter Medical Research Institute (G1001054), and the National Health and Medical Research Council (APP1045371). Funding information for this article has been deposited with FundRef.

Conflict of interest: Disclosures can be found alongside the online version of this article at erj.ersjournals.com

Copyright CERS 2016 


\section{Introduction}

Asthma is now well recognised to be a heterogeneous disease, whether assessed using clinical factors, causative triggers, response to treatments or the types of inflammation present [1]. In terms of treatment response, the measurement of cellular patterns of inflammation using induced sputum samples has proven to be useful in identifying inflammatory phenotypes of asthma. We have previously described four distinct cellular subtypes of asthma based on the presence or absence of sputum granulocytes: eosinophilic asthma, eosinophilic asthma, mixed granulocytic asthma and paucigranulocytic asthma [2]. A simple classification provides for two categories: eosinophilic asthma and non-eosinophilic asthma. However, the underlying biology of asthma inflammatory phenotypes has not been fully characterised.

Mast cells are multifunctional, tissue-dwelling cells, believed to differentiate dependent on the tissue microenvironment where they reside. On the basis of their content of neutral serine proteases and metalloexopeptidases, they have been divided into two subtypes. One subset, designated $\mathrm{MC}_{\mathrm{TC}}$, contains tryptase (TPSAB1), as well as chymase (CMA1), cathepsin $\mathrm{G}$ or carboxypeptidase $(C P A 3)$, whereas the other phenotype, designated $\mathrm{MC}_{\mathrm{T}}$, contains only tryptase. The $\mathrm{MC}_{\mathrm{T}}$ subtype is typically found at mucosal surfaces such as the nasal and bronchial epithelium in rhinitis and asthma, respectively, and the bronchial lamina propria in both health and disease [3]. The $\mathrm{MC}_{\mathrm{TC}}$ subtype, however, favours connective tissues such as normal skin and the airway smooth muscle bundles in asthma [4, 5]. Recently, real-time quantitative (q) PCR has been successfully used to characterise mast cell subtypes. An intraepithelial mast cell subtype was identified in asthma that had an unusual protease phenotype (tryptase- and carboxypeptidase A3-high, and chymase-low), was increased in subjects with T-helper (Th) 2-high asthma and predicted responsiveness to inhaled corticosteroids (ICSs) [6]. In severe asthma, the $\mathrm{MC}_{\mathrm{TC}}$ subtype was found to dominate [7].

Although there has been compelling evidence that human mast cells contribute to the pathophysiology of asthma [8] and some recent studies have suggested that mast cells play an important role in asthma, especially in uncontrolled and severe asthma [7,9], little is known regarding the presence and activity of mast cells in the airway lumen across asthma inflammatory phenotypes [10]. Since mast cell phenotype is modified by the tissue microenvironment, mast cell phenotype differences should be present in eosinophilic asthma or non-eosinophilic asthma. Whether these changes can be identified in the airway lumen and whether they have different steroid responses in asthma need to be addressed. In this study, we hypothesised that mast cell subtypes of asthma and the related gene expression profiles would associate with inflammatory phenotypes, and that mast cell subtypes would predict clinical asthma outcomes, including steroid response. Some of the results have been previously reported in the form of an abstract [11].

\section{Methods}

Subjects

Study 1 assessed mast cell gene expression in adults with stable asthma $(n=55)$ that were recruited from the John Hunter Hospital Ambulatory Care Clinic, Newcastle, Australia. The microarray data had been previously generated, and transcriptional asthma phenotypes defined and published [12]. Asthma was diagnosed according to American Thoracic Society guidelines. Healthy subjects $(n=16)$ were recruited by advertisement. Exclusion criteria were current smoking, the presence of a recent (past month) respiratory tract infection, recent asthma exacerbation, recent unstable asthma or change in maintenance therapy in the past 4 weeks. Asthma control was assessed using the Asthma Control Questionnaire (ACQ). Exhaled nitric oxide fraction $(\mathrm{FeNO})\left(\mathrm{NIOX}^{\oplus}\right.$; Aerocrine, Solna, Sweden) was measured and the skin-prick test was performed.

Study 2 assessed ICS treatment response in a subset of 49 asthmatics with predominately eosinophilic asthma or non-eosinophilic asthma (neutrophilic inflammation was rare in this population), assessed before and after treatment (1000 $\mu \mathrm{g}$ fluticasone-day ${ }^{-1}$ for 28 days) as previously published [13]. The studies were approved by the relevant institutional ethics committees: The University of Newcastle Research Ethics Committee (Study 1) and the Lower South Regional Ethics Committee of New Zealand (Study 2). The ICS response study (ACTRN12606000531516) was conducted to obtain run-in data for two larger clinical trials where establishing inflammatory phenotype and steroid responsiveness were prerequisites.

\section{Hypertonic saline challenge test, and bronchial sensitivity and reactivity indices}

Sputum induction combined with hypertonic saline challenge was performed as previously described, delivering doubling doses of nebulised $4.5 \%$ saline without $\beta$-agonist pre-treatment $[2,14-16]$. Details are available in the online supplementary material. Analyses for bronchial sensitivity and reactivity indices were undertaken by using dose-response slope (DRS) and the continuous index of responsiveness (CIR) previously described [17] (full details are available in the online supplementary material). 
Sputum analysis and asthma subtype classification

Sputum analysis was performed as previously described [2, 18]. Details are available in the online supplementary material.

Whole-genome gene expression microarrays and identification of mast cell subtypes

Microarray analyses in induced sputum samples were performed as our previous study [19]. More details are included in the online supplementary material. Mast cell subtypes, such as non- $M C, M_{T}$ and $M_{T / C P A 3}$, were identified by a molecular phenotyping approach, which was based on whether the mRNA expression of TPSAB1, CMA1 or CPA3 was present in microarray analysis of induced sputum at $\mathrm{p}<0.01$ detection value $[6,7]$.

\section{qPCR validation}

qPCR was carried out by using TaqMan reagents (Applied Biosystems, Foster City, CA, USA) and previously reported [20]. Details are provided in the online supplementary material.

\section{Clinical validation}

A prospective 1-month ICS response study was undertaken (previously reported in [13]) to validate the relationship between mast cell subtypes and inflammatory phenotypes and steroid response. Gene expression of mast cell markers was determined in 49 participants who had remaining RNA samples available. Mast cell groups were determined by qPCR detection of tryptase and CPA3 mRNA (cycle threshold $\left(C_{\mathrm{t}}\right)<37$, plus $\Delta C_{\mathrm{t}}$ versus $\beta$-actin $\left.<8\right)$. The $\mathrm{MC}_{\mathrm{T}}$ group had detection of tryptase and not CPA3, and the $\mathrm{MC}_{\mathrm{T} / \mathrm{CPA} 3}$ group had detection of both markers.

\section{Statistical analysis}

All statistical analyses for clinical and cell count data, whole-genome gene expression data, and multiple logistic regression models are described in detail in the online supplementary material.

\section{Results}

Mast cell subtype grouping and differentially expressed genes between mast cell subtypes

The microarray analysis of induced sputum found that all detection p-values for CMA1 mRNA expression were $>0.01$, indicating CMA1 expression was not detectable. Thus, mRNA expression of TPSAB1 and $C P A 3$ at the $\mathrm{p}<0.01$ detection level defined mast cell subtypes into $\mathrm{MC}_{\mathrm{T}}$ if TPSAB1 was detected $(\mathrm{n}=18)$, and $\mathrm{MC}_{\mathrm{T} / \mathrm{CPA} 3}$ if both TPSAB1 and CPA3 were detected $(\mathrm{n}=29)$. In addition, there was a non-MC group $(\mathrm{n}=8)$ where neither TPSAB1 nor CPA3 were detected. Healthy subjects had a greater proportion of the non-MC group, and participants with asthma had a higher proportion of the $\mathrm{MC}_{\mathrm{T} / \mathrm{CPA} 3}$ subtype (Chi-squared $=6.44, \mathrm{p}=0.04$ ).

There were 16 genes that were significantly different (adjusted $\mathrm{p}<0.05$ ) in expression between the three mast cell subtypes (figure $1 \mathrm{a}$ and online supplementary table E1). All 16 genes were differentially expressed in $\mathrm{MC}_{\mathrm{T} / \mathrm{CPA} 3}$ versus the non-MC group (15 upregulated, one downregulated), 12 genes were differentially expressed between $\mathrm{MC}_{\mathrm{T} / \mathrm{CPA} 3}$ and $\mathrm{MC}_{\mathrm{T}}$ subtypes (11 upregulated, one downregulated), and two genes were upregulated between the $\mathrm{MC}_{\mathrm{T}}$ subtype and the non-MC group. Expression of 11 genes was significantly higher in the $\mathrm{MC}_{\mathrm{T} / \mathrm{CPA} 3}$ subtype compared with both the $\mathrm{MC}_{\mathrm{T}}$ subtype and the non-MC group (figure $1 \mathrm{~b}$ ).

Gene expression of TPSAB1, CPA3, CMA1, HDC, CD1A, CD1B, CD1C, FCER1A and GPR56 was confirmed using $\mathrm{qPCR}$, and was highly correlated with the microarray results (data not shown). Chymase gene expression remained undetectable and all gene expression was higher in the $\mathrm{MC}_{\mathrm{T} / \mathrm{CPA} 3}$ subtype (figure 2). Differential gene expression was correlated with a number of clinical and inflammatory parameters (online supplementary table E2).

\section{Clinical features, inflammatory cells, and bronchial sensitivity and reactivity indices across mast} cell subtypes

Characteristics of participants with asthma and healthy subjects are shown in table 1 . In asthmatic subjects, the $\mathrm{MC}_{\mathrm{T} / \mathrm{CPA} 3}$ subtype had elevated FeNO and ACQ score, as well as a different sputum inflammatory cell profile (table 1 and figure $3 \mathrm{a}-\mathrm{f}$ ). There was a higher proportion of eosinophilic asthma in the $\mathrm{MC}_{\mathrm{T} / \mathrm{CPA} 3}$ subtype $(59.26 \%)$ in comparison with the non-MC group $(0 \%)$ and $\mathrm{MC}_{\mathrm{T}}(25.93 \%)$ subtype $(\mathrm{p}<0.001$; figure $3 \mathrm{~g})$. Gene expression of TPSAB1 was elevated in eosinophilic asthma versus paucigranulocytic asthma ( $\mathrm{p}<0.001$; figure $3 \mathrm{~h}$ ), and gene expression of CPA3 was elevated in eosinophilic asthma versus neutrophilic asthma $(\mathrm{p}=0.013)$ and paucigranulocytic asthma $(\mathrm{p}<0.001$; figure $3 \mathrm{i})$.

Table 2 presents the bronchial sensitivity and reactivity indices in mast cell subtypes. Forced expiratory volume in $1 \mathrm{~s}\left(\mathrm{FEV}_{1}\right)$ had fallen by $\geqslant 15 \%$ from the post-diluent baseline value in 28 out of 55 patients 


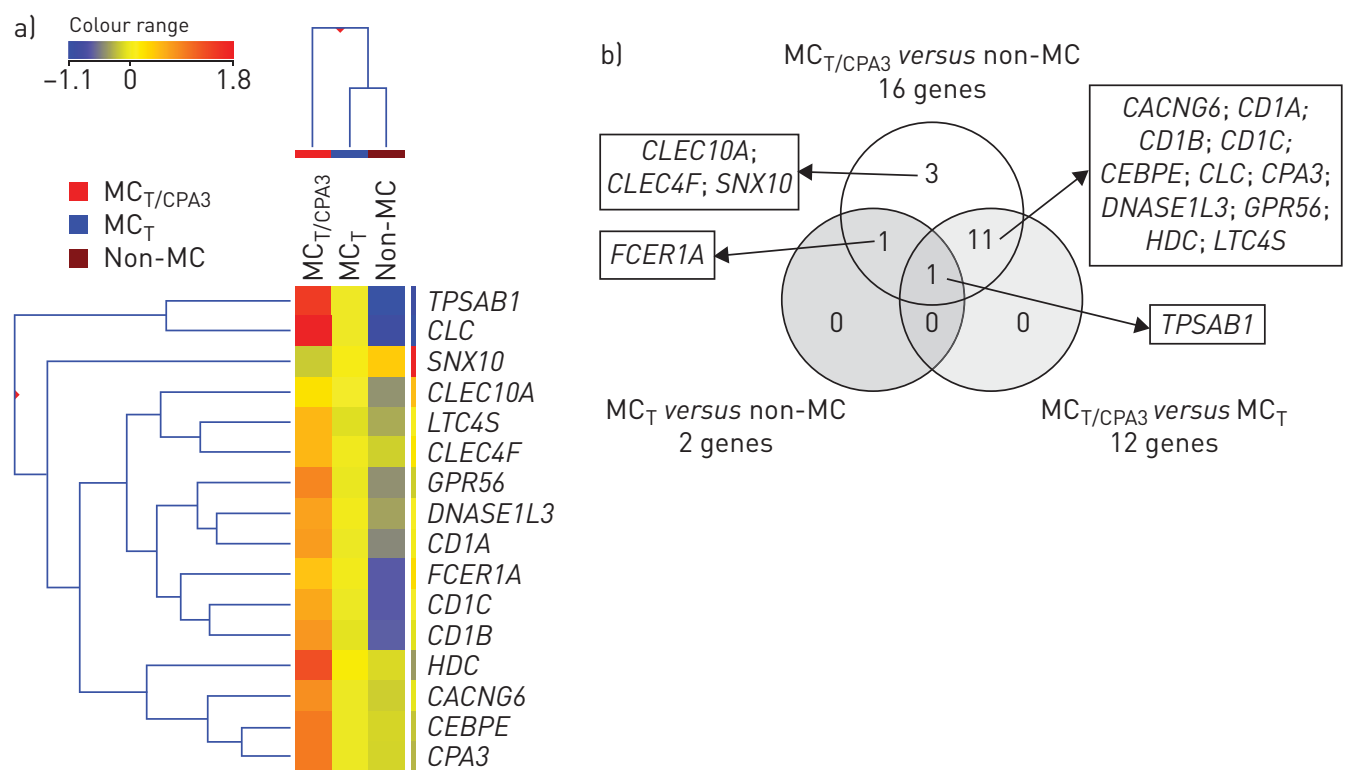

FIGURE 1 Differential gene expression between mast cell subtypes as determined by microarray analysis. a) Heatmap dendrogram of the 16 differentially expressed genes between healthy subjects and mast cell subtypes (non-MC group, $\mathrm{MC}_{\mathrm{T} / \mathrm{CPA} 3}$ and $\mathrm{MC}_{\mathrm{T}}$ ) of asthma in induced sputum, with red representing a higher level of gene expression and blue representing a lower level of gene expression. b) Venn diagram detailing the numbers and overlap of differentially expressed genes between mast cell subtypes.

with asthma during the hypertonic saline challenge test and this was similar across the mast cell groups (Chi-squared=5.28, $\mathrm{p}=0.071$ ). Although patients in the $\mathrm{MC}_{\mathrm{T} / \mathrm{CPA} 3}$ subtype had the lowest provocative dose of $4.5 \%$ hypertonic saline causing a 15\% fall in FEV1 (PD15 4.5\% saline) among three subtypes, this failed to reach statistical significance $(\mathrm{p}=0.176)$. Asthmatics with the $\mathrm{MC}_{\mathrm{T} / \mathrm{CPA} 3}$ subtype had an increased $\mathrm{DRS}$ and CIR compared with the other two groups ( $\mathrm{p}=0.01$ and $\mathrm{p}=0.025$, respectively).

Relationship of mast cell subtype with asthma control levels, airway obstruction and ICS use In subjects with uncontrolled asthma (ACQ score $>0.75$ ), there was a greater proportion of the $\mathrm{MC}_{\mathrm{T} / \mathrm{CPA} 3}$ subtype $(72.7 \%)$ and smaller proportion of the non-MC group $(0.0 \%)$ compared with $37.9 \%$ and $24.1 \%$, respectively, in well-controlled asthma (ACQ score $\leqslant 0.75)(\mathrm{p}=0.014)$. Furthermore, mRNA expression of CPA3 was higher in uncontrolled asthma (controlled asthma 0.90 (interquartile range (IQR) 0.08-2.63) versus uncontrolled asthma $2.01(0.47-14.72), \mathrm{p}=0.047)$. CPA3 expression also correlated with bronchial sensitivity indices (online supplementary table E2).

Whether mast cell subtypes varied with asthma severity assessed by Global Initiative for Asthma guideline criteria [21] was also analysed. The mRNA expression of TPSAB1 was increased in severe asthma in comparison with mild-to-moderate asthma (4.07 (IQR 1.27-7.6) versus 0.71 (IQR 0.33-2.38), $\mathrm{p}=0.045$ ). There was no significant difference in TPSAB1 and CPA3 mRNA expression in participants taking ICS versus those not taking ICS.

TPSAB1 and CPA3 correlated with airway sensitivity and with airway obstruction (online supplementary table E2). In patients with FEV1/forced vital capacity (FVC) $<70 \%$, TPSAB1 and CPA3 mRNA was much higher than those with FEV1/FVC $\geqslant 70 \%$ (2.61 (IQR 0.47-6.39) versus 0.61 (IQR 0.18-1.95), $\mathrm{p}=0.017$; and 2.28 (IQR 0.50-15.96) versus 0.86 (IQR 0.08-2.55), $\mathrm{p}=0.015$, respectively).

\section{Multivariable logistic regression}

In the initial univariate analyses, atopy, body mass index (BMI), FeNO, FEV $1 \%$ predicted (\% pred), DRS, TPSAB1 and CPA3 were associated with airway eosinophilia. Both FeNO (OR 1.01, p=0.041) and CPA3 (OR 1.17, $\mathrm{p}=0.018$ ) were significant predictors of eosinophilic asthma after controlling for atopy, BMI, FEV1 \% pred, ACQ score, ICS dose, DRS and TPSAB1 (online supplementary table E3). Furthermore, although both $\mathrm{MC}_{\mathrm{T}}(\mathrm{OR} 1.21, \mathrm{p}=0.04)$ and $\mathrm{MC}_{\mathrm{T} / \mathrm{CPA} 3}(\mathrm{OR} 1.99, \mathrm{p}<0.001)$ subtypes predicted eosinophilic asthma, the $\mathrm{MC}_{\mathrm{T} / \mathrm{CPA} 3}$ subtype was superior (OR 1.35, $\mathrm{p}=0.044$ (figure 4 ). In a model of predictions of mast cell subtypes, ICS use was a negative predictor of $\mathrm{MC}_{\mathrm{T} / \mathrm{CPA} 3}$ subtype (OR 0.99, $\mathrm{p}=0.016$ ) and asthmatic subjects with the $\mathrm{MC}_{\mathrm{T} / \mathrm{CPA} 3}$ subtype had poorer asthma control $(\mathrm{OR} 1.28, \mathrm{p}=0.008$; online supplementary table E3). 

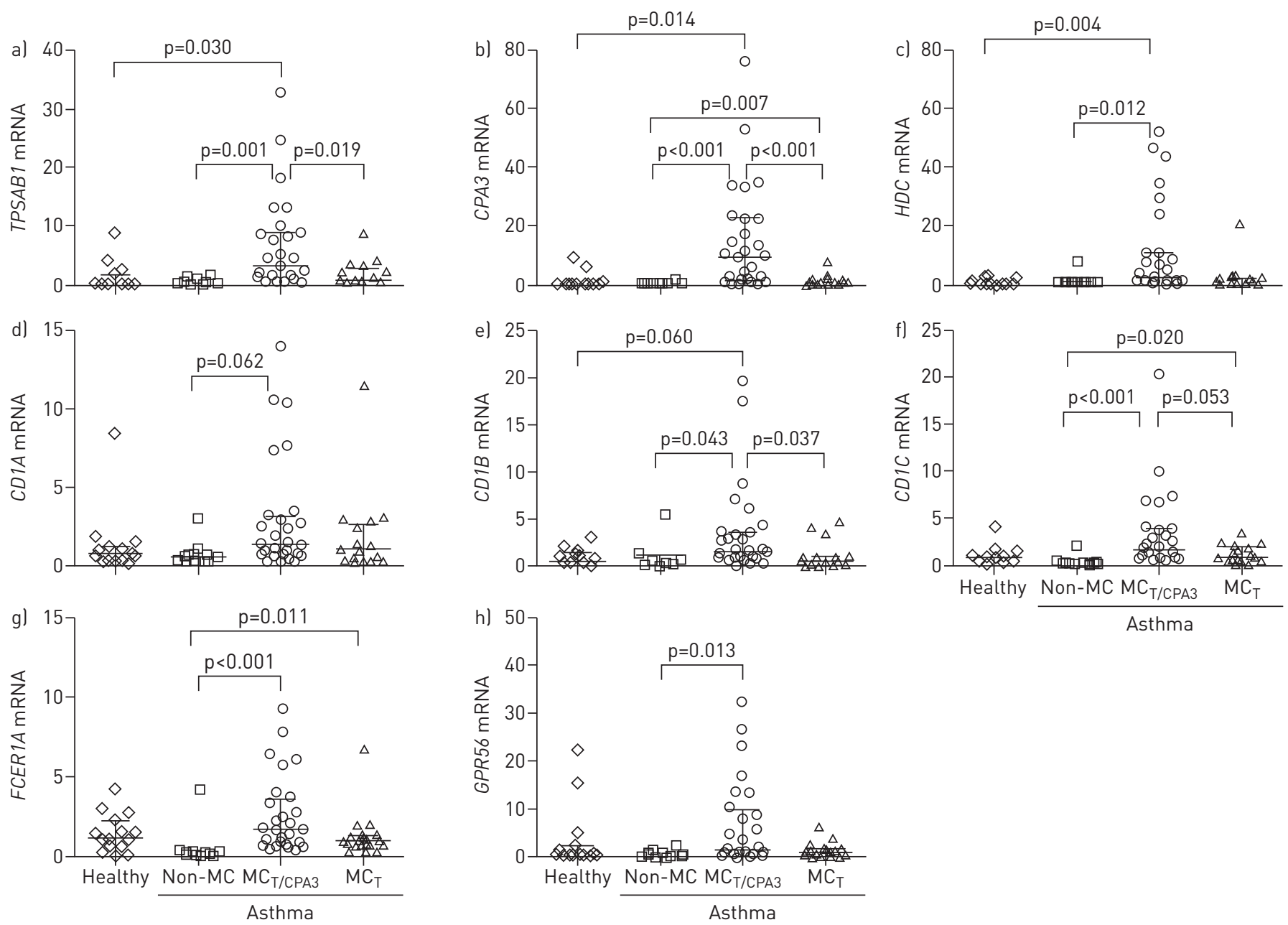

Asthma

FIGURE 2 Sputum expression of mast cell signature genes in healthy controls and mast cell subtypes of asthma measured by quantitative PCR: a) TPSAB1, b) CPA3, c) HDC, d) CD1A, e) CD1B, f) CD1C, g) FCER1A and h) GPR56. Data are presented as fold change (median and upper/lower quartile (error bars)) versus the mean of the healthy control group.

\section{Clinical validation and ICS response}

30 patients were of the $\mathrm{MC}_{\mathrm{T}}$ subtype and 19 patients were of the $\mathrm{MC}_{\mathrm{T} / \mathrm{CPA} 3}$ subtype. In the $\mathrm{MC}_{\mathrm{T}}$ subtype, $16(53 \%)$ subjects had eosinophilic asthma; in the $\mathrm{MC}_{\mathrm{T} / \mathrm{CPA} 3}$ subtype, $15(79 \%)$ subjects had eosinophilic asthma. CPA3 mRNA expression had significantly increased odds ratio (OR 1.28, 95\% CI 1.08-1.5), $\mathrm{p}=0.005$ ) in predicting eosinophilic asthma after adjusting for TPSAB1, ACQ score, $\mathrm{FEV} 1$, provocative dose of AMP causing a 20\% fall in FEV1 (PD20 AMP) and FeNO.

The ICS response (1000 $\mu \mathrm{g}$ fluticasone for 28 days) was assessed in terms of $\triangle \mathrm{ACQ}$ score, $\Delta \mathrm{FEV} 1 \%$ pred, $\Delta \mathrm{PD} 20 \mathrm{AMP}$ and $\Delta \mathrm{FeNO}_{\mathrm{NO}}$. The $\mathrm{MC}_{\mathrm{T} / \mathrm{CPA}}$ subtype was compared with subjects with the $\mathrm{MC}_{\mathrm{T}}$ subtype (table 3). The $\mathrm{MC}_{\mathrm{T} / \mathrm{CPA} 3}$ subtype predicted a greater change in ACQ score, FEV1 \% pred and FeNO (table 3).

Accordingly, the gene expression profiles were significantly altered between mast cell subtypes, where the expression of TPSAB1, CPA3, FCER1A, GPR56, CLC and DNASE1L3 was higher in the $\mathrm{MC}_{\mathrm{T} / \mathrm{CPA} 3}$ compared with the $\mathrm{MC}_{\mathrm{T}}$ subtype (figure 5). ICS treatment did not alter gene expression in the $\mathrm{MC}_{\mathrm{T}}$ subtype, except for FCER1A expression, but dramatically downregulated gene expression of CPA3, FCER1A, CLC and DNASE1L3 in the $\mathrm{MC}_{\mathrm{T} / \mathrm{CPA} 3}$ subtype (figure 5). GPR56 expression was not responsive to ICS treatment and CD1C expression did not differ in this cohort (data not shown). Relationships between gene expression in mast cell subtypes and clinical outcomes are detailed in online supplementary table E3.

\section{Discussion}

The results of this study, for the first time to the best of our knowledge, provide evidence for the subtype and differential gene expression profile of mast cells in induced sputum of asthma. Subjects with asthma had increased biomarkers of mast cells compared with healthy controls and could be classified into 
TABLE 1 Characteristics of healthy and asthma subjects grouped by mast cell subtype

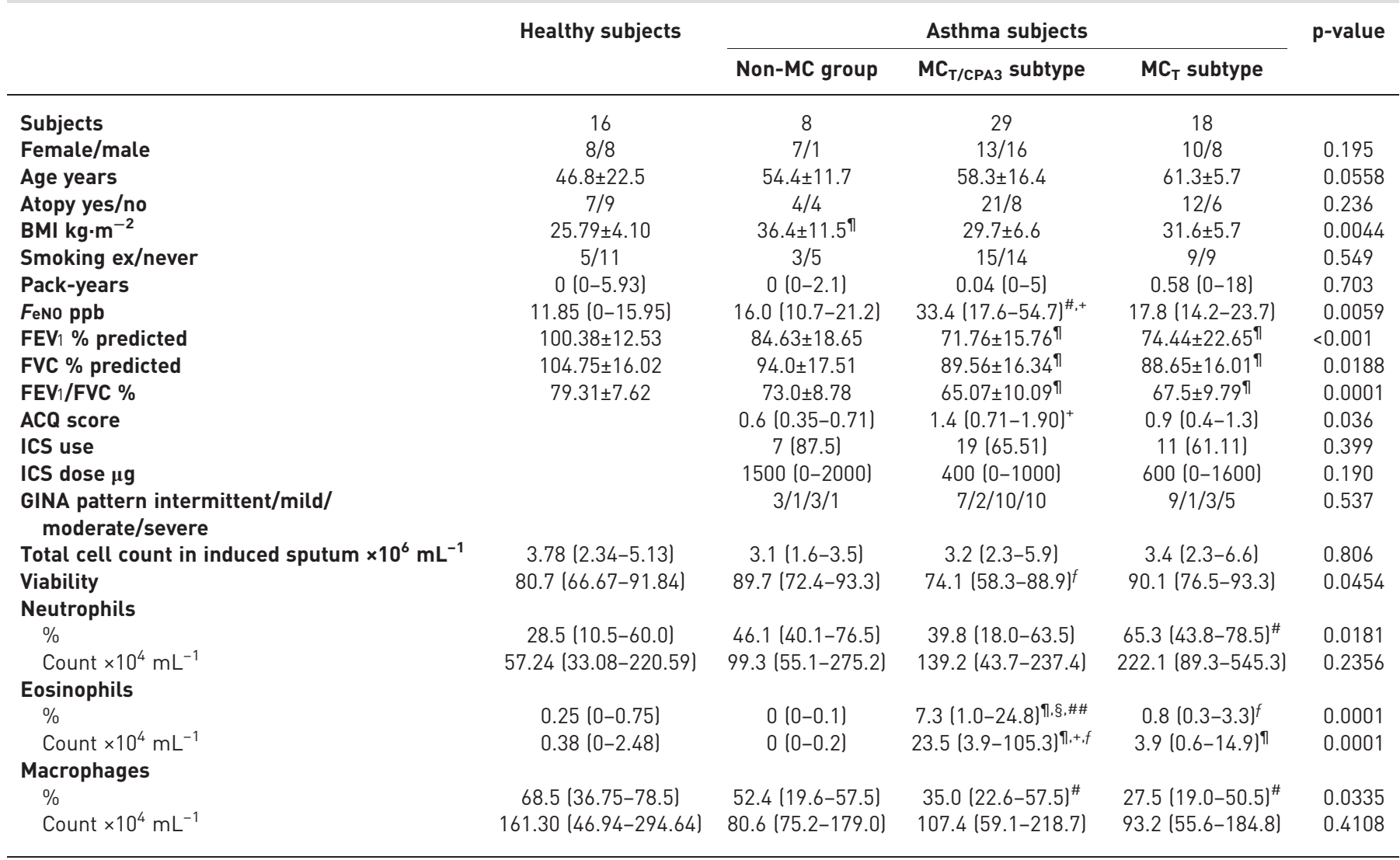

Data are presented as $\mathrm{n}$, mean $\pm \mathrm{SD}$, median (interquartile range) or $\mathrm{n}(\%)$, unless otherwise stated. BMI: body mass index; FeNo: exhaled nitric oxide fraction; FEV1: forced expiratory volume in $1 \mathrm{~s}$; FVC: forced vital capacity; ACQ: Asthma Control Questionnaire; ICS: inhaled corticosteroid;

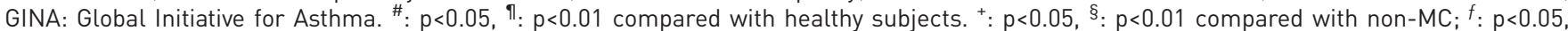
\#\# : $\mathrm{p}<0.01$ compared with $\mathrm{MC}_{\mathrm{T}}$.

specific mast cell subtypes based on a molecular phenotyping approach. The $\mathrm{MC}_{\mathrm{T} / \mathrm{CPA} 3}$ subtype had similar demographic and clinical characteristics to the $\mathrm{MC}_{\mathrm{T}}$ subtype and non-MC group; however, there was an increase in $\mathrm{FeNO}$, sputum eosinophil counts and proportion, bronchial sensitivity and reactivity, and worse asthma control. Furthermore, the $\mathrm{MC}_{\mathrm{T} / \mathrm{CPA} 3}$ subtype had a differential gene expression profile, with elevated expression of several genes, including CD1A, CD1B, CD1C, CEBPE, CLC, CLEC4F, DNASE1L3, GPR56, FCER1A, CACNG6, HDC and LTC4S. In addition, the $\mathrm{MC}_{\mathrm{T} / \mathrm{CPA} 3}$ subtype was associated with eosinophilic asthma rather than other cellular inflammatory phenotypes (neutrophilic asthma, mixed granulocytic asthma or paucigranulocytic asthma). Multivariate logistic regression models and the further clinical validation study strongly suggested that $C P A 3$, or the $\mathrm{MC}_{\mathrm{T} / \mathrm{CPA} 3}$ subtype, is associated with underlying pathobiology of airway eosinophilia or eosinophilic asthma, either as a cause or a consequence and predicts responsiveness to corticosteroids, with improvements in bronchodilation and airway hyperresponsiveness (AHR).

In general, mast cell subtype is assessed by a standard immunohistochemistry (IHC) approach. However, this limits the study of airway luminal mast cells because mast cells are rarely detectable in induced sputum $[2,16]$. Recent studies have highlighted the potential for molecular phenotyping of mast cells based on gene expression of mast cell proteases [6,7]. We used this approach in this study and mast cell subtype classification was based on whether the mRNA expression of TPSAB1, CMA1 or CPA3 was present in induced sputum. Unexpectedly, mRNA expression of CMA1 was below the limits of detection in our sputum samples. This has been observed previously $[6,7,10]$ and we could confirm the existence of a different mast cell subtype in asthma, with expression of $C P A 3$. Thus, $\mathrm{MC}_{\mathrm{T} / \mathrm{CPA} 3}$ as a nomenclature, for the first time, was used in this study.

Our study also identified 15 differential genes that were upregulated in the $\mathrm{MC}_{\mathrm{T} / \mathrm{CPA} 3}$ subtype asthma. Those genes related to pathogenic characteristics of the $\mathrm{MC}_{\mathrm{T} / \mathrm{CPA} 3}$ subtype can be classified into several kinds. 


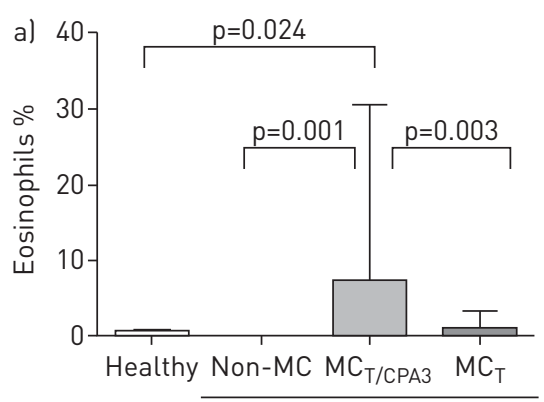

Asthma

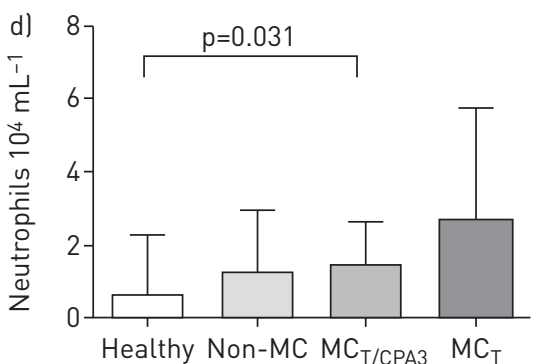

Asthma

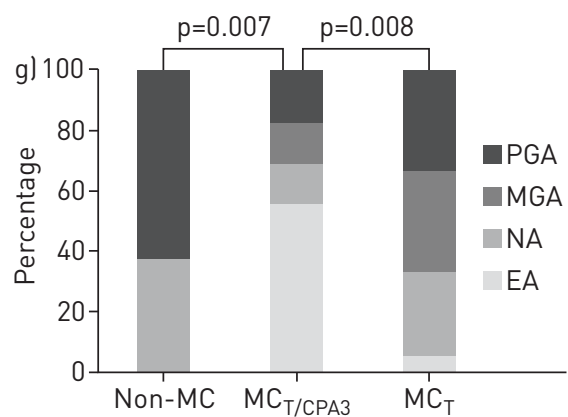

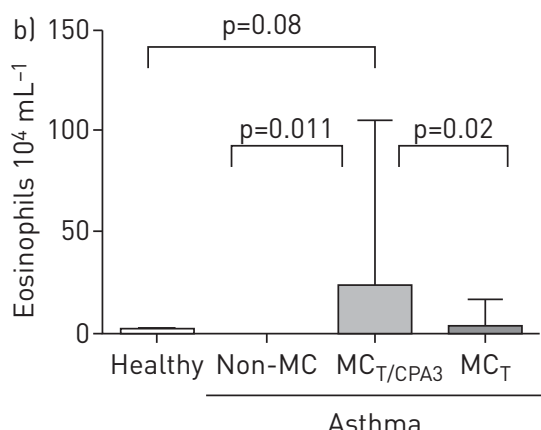

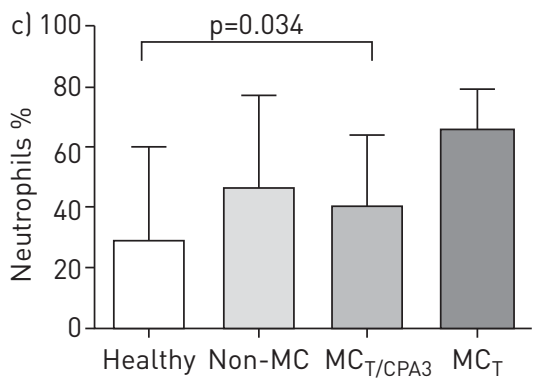

Asthma
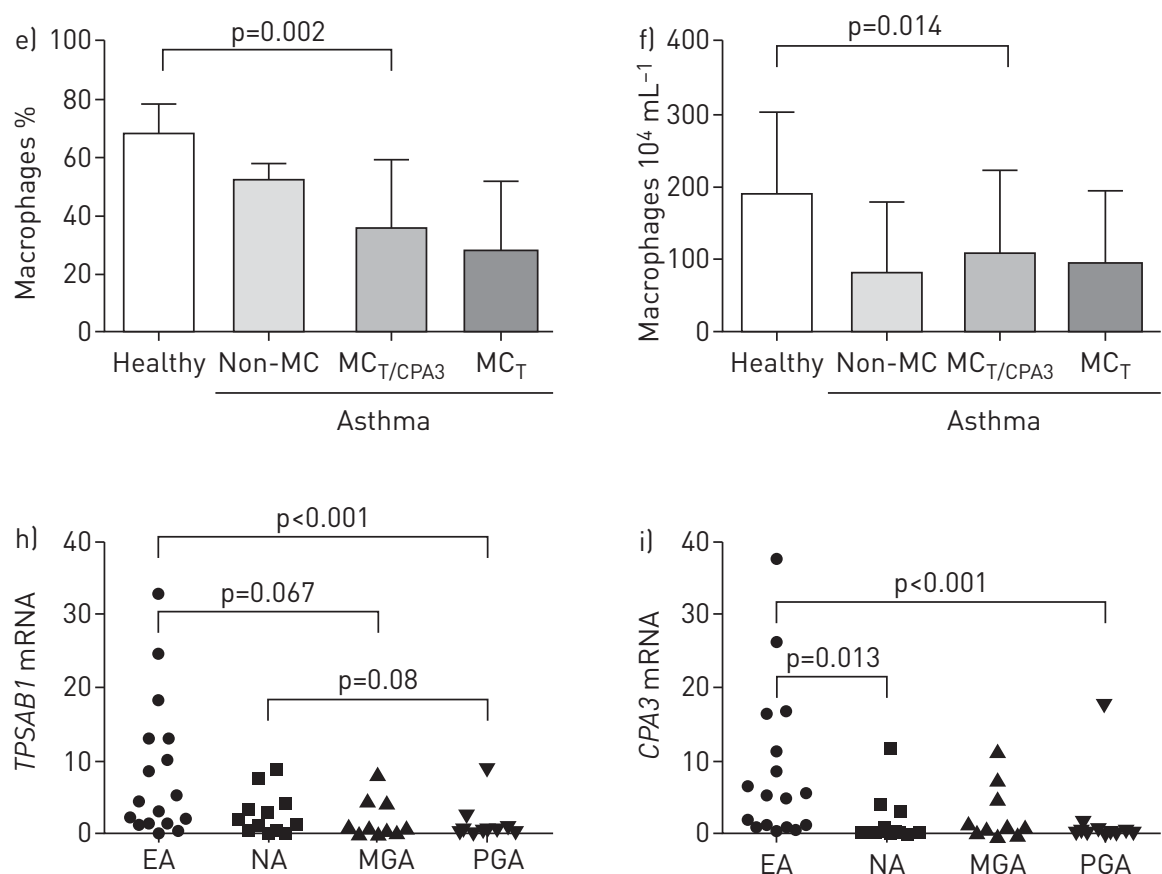

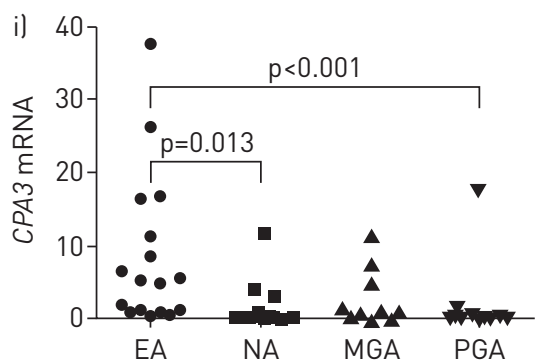

FIGURE 3 a-f) Sputum inflammatory cells in healthy subjects and mast cell subtypes of asthma (median and upper quartile (error bar)], g) cellular phenotypes in mast cell subtypes, and h, i) mRNA expression of mast cell markers as determined by quantitative PCR (TPSAB1 and CPA3, respectively) (fold change versus the mean of the healthy control group) in inflammatory phenotypes of asthma in induced sputum. EA: eosinophilic asthma; NA: neutrophilic asthma; MGA: mixed granulocytic asthma; PGA: paucigranulocytic asthma.

First, there are mast cell-specific biomarkers such as TPSAB1 and CPA3, and their expression was related to clinical parameters. Those mast cells also had increased expression of some genes, e.g. HDC and LTC4S, which are known to induce eosinophil recruitment. FceRI receptors play an important role in allergen-induced mediator release and antigen presentation by mast cells. FCER1A encodes a ligand-binding subunit of the high-affinity IgE receptor and is a major susceptibility locus for serum $\operatorname{IgE}$

TABLE 2 Bronchial sensitivity and reactivity indices in subjects with asthma

\begin{tabular}{lcccc} 
& Non-MC group & $\mathrm{MC}_{\mathrm{T}}$ subtype & $\mathrm{MC}_{\mathrm{T} / \mathrm{CPA3}}$ subtype & $\mathrm{p}$-value \\
\hline PD15 4.5\% saline $\mathrm{mL}^{\#}$ & $9.84 \pm 8.46$ & $8.15 \pm 3.78$ & $4.93 \pm 4.79$ & 0.176 \\
Bronchial reactivity indices & & & & \\
DRS \% $\mathrm{mL}^{-1}$ & $4.83 \pm 10.39$ & $1.12 \pm 1.17$ & $9.90 \pm 16.94^{\S}$ & 0.010 \\
CIR & $-0.13 \pm 0.88$ & $-0.10 \pm 0.43$ & $0.46 \pm 0.69^{+. \S}$ & 0.025 \\
\hline
\end{tabular}

Data are presented as mean \pm SD, unless otherwise stated. PD15: provocative dose of $4.5 \%$ hypertonic saline causing a $15 \%$ fall in forced expiratory volume in $1 \mathrm{~s}$; DRS: dose-response slope; CIR: continuous index of responsiveness. ${ }^{\#}$ : $n=3,6$ and 19 for non-MC, $M C_{T}$ and $M C_{T / C P A 3}$, respectively; ${ }^{{ }^{n}}: n=6,14$ and 24 for non$M C, M C_{T}$ and $M_{T / C P A 3}$, respectively. ${ }^{+}: p<0.05$ compared with non-MC; ${ }^{\S}$ : $p<0.05$ compared with $\mathrm{MC}_{\mathrm{T}}$. 
OR $(95 \% \mathrm{CI})$

Non-MC group

MC subtype

$\mathrm{MC}_{\mathrm{T}}$ subtype

$M C_{T / C P A 3}$ subtype

$\mathrm{MC}_{\mathrm{T} / \mathrm{CPA} 3}$ versus $\mathrm{MC}_{\mathrm{T}}$ subtype

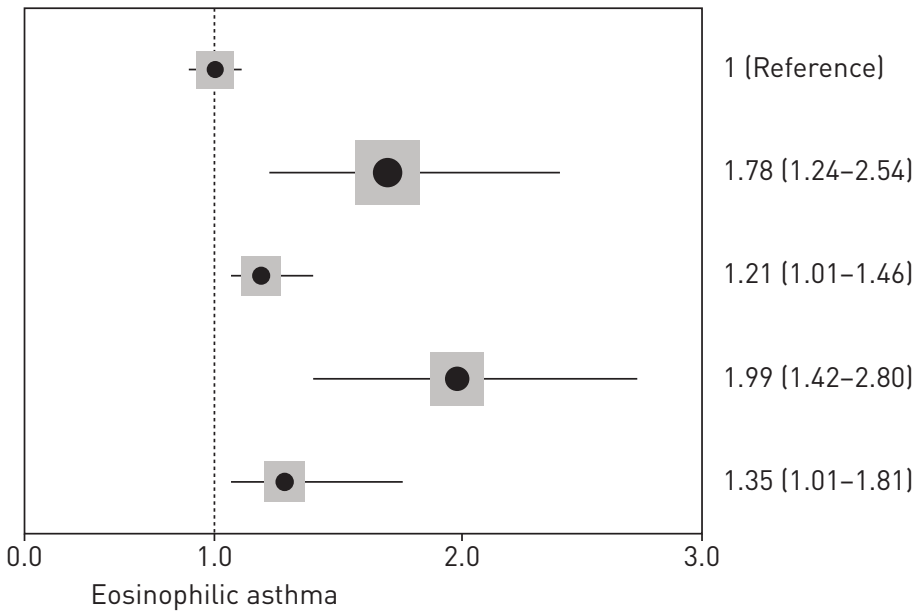

FIGURE 4 Forest plot of mast cell subtypes in predicting eosinophilic asthma.

levels [22]. RAJAKULASINGAM et al. [23] found allergen provocation in asthmatics resulted in increased mRNA expression of FCER1A predominantly on airway eosinophils. Secondly, CEBPE and CLC are related to eosinophils. CEBPE, as the CCAAT enhancer binding protein, has been shown to be essential for the transcriptional regulation of the eosinophil granulocyte gene, the major basic protein [24]. CLC, expressing Charcot-Leyden crystal protein, is an important eosinophil product. Thirdly, we observed increased expression of some genes expressed on macrophages and dendritic cells that are involved in antigen presentation. Human group $1 C D 1$ molecules $(C D 1 A, C D 1 B, C D 1 C)$ mediate presentation of microbial lipid and glycolipid antigens to T-cells. These CD1 molecules differentially sample distinct endocytic compartments that may contain different sets of lipid antigens derived from intracellular microbes and activate antigen-specific T-cells [25]. CLEC4F and CLEC10A, as C-type lectins, may play an important role in modulating glycolipid presentation in macrophages [26]. Fourthly, we identified upregulation of other genes, such as CACNG6, GPR56 and DNASE1L3, that are less explored in asthma. Variants of CACNG6 might be associated with the risk of aspirin-intolerant asthma [27]. GPR56, as an orphan G protein-coupled receptor, has been studied more in melanoma and brain malformation, but not airway inflammation [28]. However, PENG et al. [29] recently found GPR56 expression is a common trait of human cytotoxic lymphocytes and might affect the migratory properties of these cells, thereby contributing to Th2-mediated airway inflammation [30]. We have recently identified a biomarker signature of CPA3, CLC and DNASE1L3 that discriminated eosinophilic asthma from other asthma inflammatory phenotypes [20].

In this study, we assessed AHR using the indirect-acting stimulus of hypertonic saline that has previously been related to intraepithelial mast cell numbers [31]. Patients with the $\mathrm{MC}_{\mathrm{T} / \mathrm{CPA} 3}$ subtype had increased DRS and CIR. A small sample size could account for the lack of statistical significance in PD15 4.5\% saline. BRIGHTLING et al. [5] proved that the presence of mast cells within the airway smooth muscle could contribute to the development of AHR and that $83 \%$ of the mast cells in airway smooth muscle were of the $\mathrm{MC}_{\mathrm{TC}}$ subtype.

The effects of ICS on the $\mathrm{MC}_{\mathrm{TC}}$ subtype in published studies remain controversial [32-34]. While our cross-sectional study did not find a difference in mast cell biomarkers between subjects who were using and

TABLE 3 Inhaled corticosteroid response after 28 days of therapy in three mast cell subtypes

\begin{tabular}{lccc} 
& MC $_{\mathbf{T}}$ subtype & MC $_{\text {T/CPA3 }}$ subtype & p-value \\
\hline Subjects & 30 & 19 & \\
$\Delta$ ACQ score & $-0.6(-1.4-0.0)$ & $-1.2(-2.3--0.7)$ & 0.043 \\
$\Delta$ FEV1 \% predicted & $10.7(3.9-19.1)$ & $25.1(7.4-45.7)$ & 0.035 \\
$\Delta$ PD20 AMP & $3.0(0.6-5.0)$ & $3.5(2.4-5.7)$ & 0.353 \\
$\Delta$ FeN0 & $-35.7(-72.4--1.7)$ & $-60.1(-76.7--42.4)$ & 0.055 \\
\hline
\end{tabular}

Data are presented as $\mathrm{n}$ or median (interquartile range), unless otherwise stated. ACQ: Asthma Control Questionnaire; FEV1: forced expiratory volume in $1 \mathrm{~s}$; PD20 AMP: provocative dose of AMP causing a $20 \%$ fall in $\mathrm{FEV}_{1}$; FenO: exhaled nitric oxide fraction. 

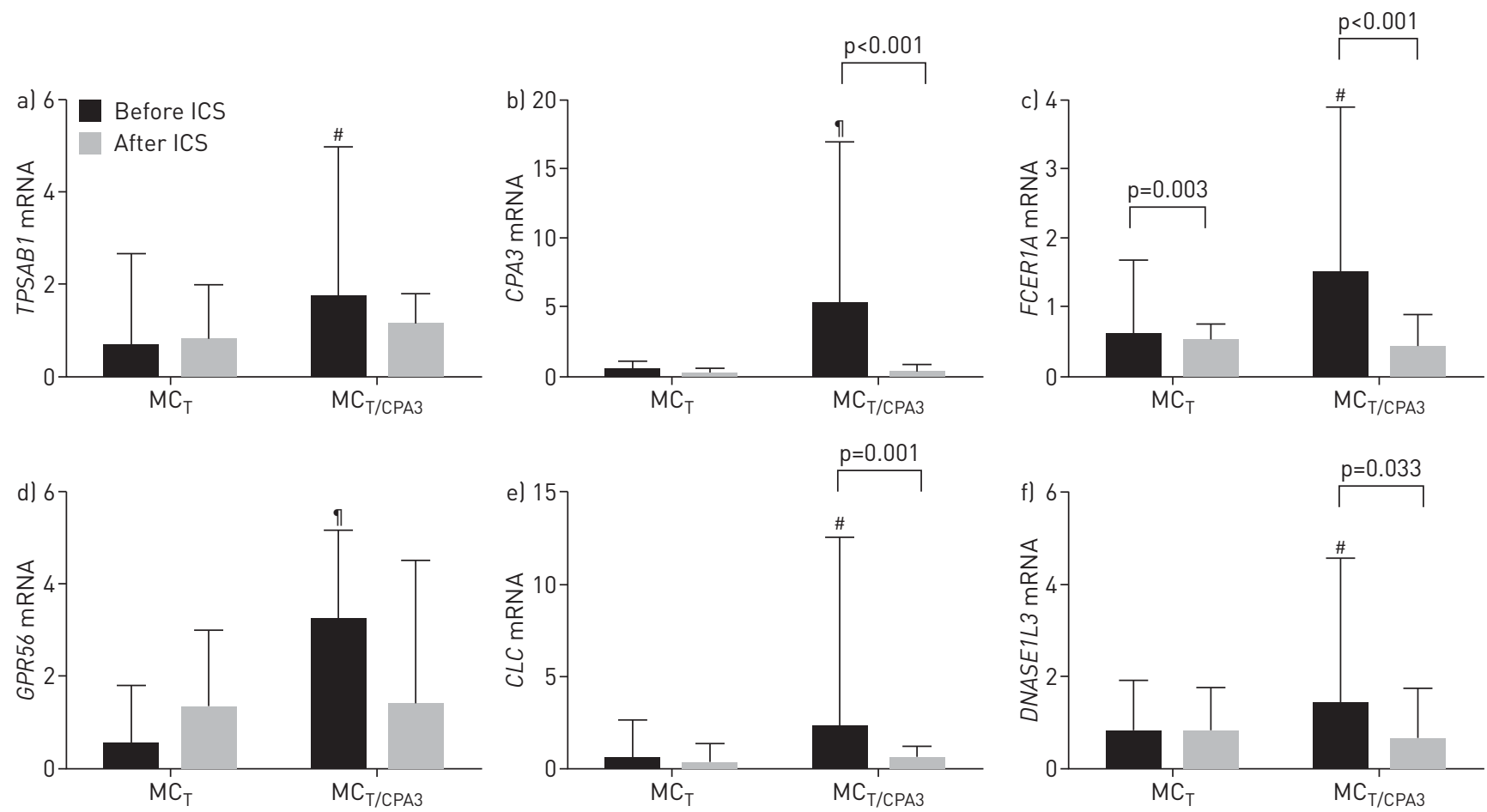

FIGURE 5 Expression of selected signature genes (measured by quantitative PCR) of mast cell subtypes in induced sputum cells before and after inhaled corticosteroid (ICS) treatment: a) TPSAB1, b) CPA3, c) FCER1A, d) GPR56, e) CLC and f) DNASE1L3. Data are presented as fold change (median and upper quartile (error bar)) versus the mean of all samples before ICS treatment. \#: Dunn's post hoc test $p<0.05$ versus the non-MC group; ๆ: Dunn's post hoc test $\mathrm{p}<0.05$ versus the $M C_{\mathrm{T}}$ subtype.

those not using ICS, a multivariate logistic regression model indicated that higher ICS dose was associated with lower mast cells, suggesting that ICS reduces the numbers of $\mathrm{MC}_{\mathrm{T} / \mathrm{CPA3}}$. Our further 28-day cohort study indicated that the $\mathrm{MC}_{\mathrm{T} / \mathrm{CPA} 3}$ subtype had a greater response to ICS with changes in ACQ score, FEV1 $\%$ pred, PD20 AMP and FeNO, as well as downregulation of our mast cell signature genes. Expression of TPSAB2 and CPA3 has been previously identified as increased in Th2-high asthma, being associated with interleukin (IL)-4, -13 and -5 gene expression in sputum [35]. Dougherty et al. [6] also showed the $\mathrm{MC}_{\mathrm{TC}}$ subtype in the airway epithelium predicted ICS response in Th2-driven asthma. However, BALZAR et al. [7] found that in these more severe corticosteroid-treated groups, a consistent shift in the $\mathrm{MC}_{\mathrm{T}}$ population toward the $\mathrm{MC}_{\mathrm{TC}}$ subtype occurs. In addition, they also showed low gene expression of chymase; however, they did confirm a correlation between chymase-positive and CPA3-positive mast cells using IHC [7]. Corticosteroid insensitivity related to the $\mathrm{MC}_{\mathrm{TC}}$ or $\mathrm{MC}_{\mathrm{T} / \mathrm{CPA} 3}$ subtype needs to be further explored [36, 37].

Our study has some limitations. First, although differential gene expression profiling between mast cell subtypes was found, some genes, e.g. CD1B, CD1C, CLEC4F, CLEC10A, CACNG6, DNASE1L3 and GPR56, cannot be explained in mast cell subtypes or airway eosinophilia. Cross-talk between mast cells and other cells such as macrophages, natural killer cells and cytotoxic T-lymphocytes might involve activation of these genes. Second, IHC as a classical approach for assessing mast cell subtypes was not applied in this study because of the mast cell paucity in induced sputum. Therefore, there is a possibility that these results reflect the level of mast cells in the sputum samples rather than true mast cell subtypes and higher tryptase expression in the $\mathrm{MC}_{\mathrm{T} / \mathrm{CPA} 3}$ may support this hypothesis, which should be further investigated in future studies. However, we consider our molecular assessment of mast cell gene expression detection using qPCR to be superior as we can measure expression in a larger sample volume (using $100 \mu$ of sputum plugs, as opposed to dispersed cells), the assays are controlled for observer error and are highly specific for mast cell genes, and the technique is not subject to cell loss (unlike IHC for sputum). Subtype classification was determined by detection of mRNA, not the level of expression, suggesting the presence of different phenotypes of mast cells, some which have very higher levels of CPA3 expression. Third, in our prospective clinical validation study, there were no subjects with neutrophilic asthma at baseline and so the analysis regarding ICS response was performed in non-eosinophilic asthma, but not neutrophilic asthma. The effect of mast cell subtypes on response of ICS in neutrophilic asthma will need further investigation. Fourth, the sample size was small in our prospective clinical validation study and so we did not have enough power to fully understand the effects of ICS on the $\mathrm{MC}_{\mathrm{T} / \mathrm{CPA} 3}$ subtype. 


\section{Conclusions}

In conclusion, mast cell subtypes of asthma in induced sputum have been established by a molecular phenotyping approach, in which the $\mathrm{MC}_{\mathrm{T} / \mathrm{CPA} 3}$ subtype was the most common and associated with differential gene expression, increased bronchial sensitivity and reactivity, eosinophilic inflammation, and greater ICS responses. These findings provide further evidence for the important role that mast cells play in human asthma, as well as for the identification of new noncorticosteroid therapeutic targets.

\section{Acknowledgements}

We acknowledge technical support from Naomi Fibbens and Lakshitha Gunawardhana, and clinical support from Kelly Steel and Calida Garside from the University of Newcastle and Hunter Medical Research Institute (Australia).

\section{References}

Wenzel SE. Asthma phenotypes: the evolution from clinical to molecular approaches. Nat Med 2012; 18: 716-725.

2 Simpson JL, Scott R, Boyle MJ, et al. Inflammatory subtypes in asthma: assessment and identification using induced sputum. Respirology 2006; 11: 54-61.

3 Carter RJ, Bradding P. The role of mast cells in the structural alterations of the airways as a potential mechanism in the pathogenesis of severe asthma. Curr Pharm Des 17: 685-698.

4 Irani AA, Schechter NM, Craig SS, et al. Two types of human mast cells that have distinct neutral protease compositions. Proc Natl Acad Sci USA 1986; 83: 4464-4468.

5 Brightling CE, Bradding P, Symon FA, et al. Mast-cell infiltration of airway smooth muscle in asthma. $N$ Engl J Med 2002; 346: 1699-1705.

6 Dougherty RH, Sidhu SS, Raman K, et al. Accumulation of intraepithelial mast cells with a unique protease phenotype in $\mathrm{T}_{\mathrm{H}}$ 2-high asthma. J Allergy Clin Immunol 2010; 125: 1046-1053.

7 Balzar S, Fajt ML, Comhair SAA, et al. Mast cell phenotype, location, and activation in severe asthma. Am J Resp Crit Care Med 2011; 183: 299-309.

8 Bradding P, Walls AF, Holgate ST. The role of the mast cell in the pathophysiology of asthma. J Allergy Clin Immunol 2006; 117: 1277-1284.

9 Andersson CK, Bergqvist A, Mori M, et al. Mast cell-associated alveolar inflammation in patients with atopic uncontrolled asthma. J Allergy Clin Immunol 2011; 127: 905-912.

10 Fajt ML, Wenzel SE. Mast cells, their subtypes, and relation to asthma phenotypes. Ann Am Thorac Soc 2013; 10: S158-S164.

11 Wang G, Baines KJ, Hu JJ, et al. Mast cell-based phenotypes of asthma in induced sputum samples. Respirology 2013; 18: 108

12 Baines KJ, Simpson JL, Wood LG, et al. Transcriptional phenotypes of asthma defined by gene expression profiling of induced sputum samples. J Allergy Clin Immunol 2011; 127: 153-160.

13 Cowan DC, Cowan JO, Palmay R, et al. Effects of steroid therapy on inflammatory cell subtypes in asthma. Thorax 2010; 65: 384-390.

14 Gibson P, Wlodarczyk J, Hensley M, et al. Epidemiological association of airway inflammation with asthma symptoms and airway hyperresponsiveness in childhood. Am J Resp Crit Care Med 1998; 158: 36-41.

15 Anderson SD, Schoeffel R, Finney M. Evaluation of ultrasonically nebulised solutions for provocation testing in patients with asthma. Thorax 1983; 38: 284-291.

16 Cai Y, Carty K, Henry RL, et al. Persistence of sputum eosinophilia in children with controlled asthma when compared with healthy children. Eur Respir J 1998; 11: 848-853.

17 Cisneros C, García-Río F, Romera D, et al. Bronchial reactivity indices are determinants of health-related quality of life in patients with stable asthma. Thorax 2010; 65: 795-800.

18 Simpson JL, McElduff P, Gibson PG. Assessment and reproducibility of non-eosinophilic asthma using induced sputum. Respiration 2010; 79: 147-151.

19 Baines KJ, Simpson JL, Wood LG, et al. Transcriptional phenotypes of asthma defined by gene expression profiling of induced sputum samples. J Allergy Clin Immunol 2011; 127: 153-160.

20 Baines KJ, Simpson JL, Wood LG, et al. Sputum gene expression signature of 6 biomarkers discriminates asthma inflammatory phenotypes. J Allergy Clin Immunol 2014; 133: 997-1007.

21 Global Initiative for Asthma. Global strategy for asthma management and prevention, 2015. http://www.ginasthma. org/documents/4 Date last accessed: May 1, 2015.

22 Potaczek DP, Michel S, Sharma V, et al. Different FCER1A polymorphisms influence IgE levels in asthmatics and non-asthmatics. Ped Allergy Immunol 2013; 24: 441-449.

23 Rajakulasingam K, Till S, Ying S, et al. Increased expression of high affinity IgE (FceRI) receptor- $\alpha$ chain mRNA and protein-bearing eosinophils in human allergen-induced atopic asthma. Am J Resp Crit Care Med 1998; 158: 233-240.

24 Du J, Stankiewicz MJ, Liu Y, et al. Novel combinatorial interactions of GATA-1, PU.1, and C/EBPepsilon isoforms regulate transcription of the gene encoding eosinophil granule major basic protein. J Biol Chem 2002; 277: 43481-43494.

25 Sugita M, Brenner MB. T lymphocyte recognition of human group $1 \mathrm{CD} 1$ molecules: implications for innate and acquired immunity. Semin Immunol 2000; 12: 511-516.

26 Yang CY, Chen JB, Tsai TF, et al. CLEC4F is an inducible C-type lectin F4/80-positive cells and is involved in alpha-galactosylceramide presentation in liver. PLoS One 2013; 8: e65070.

27 Lee J, Kim J, Bae J, et al. Association of CACNG6 polymorphisms with aspirin-intolerance asthmatics in a Korean population. BMC Med Genet 2010; 11: 138.

28 Jin Z, Luo R, Piao X. GPR56 and its related diseases. Prog Mol Biol Transl Sci 2009; 89: 1-13.

29 Peng Y-M, van de Garde MDB, Cheng K-F, et al. Specific expression of GPR56 by human cytotoxic lymphocytes. J Leukoc Biol 2011; 90: 735-740.

30 Visekruna A, Ritter J, Scholz T, et al. Tc9 cells, a new subset of $\mathrm{CD} 8^{+} \mathrm{T}$ cells, support Th2-mediated airway inflammation. Eur J Immunol 2013; 43: 606-618. 
31 Gibson PG, Saltos N, Borgas T. Airway mast cells and eosinophils correlate with clinical severity and airway hyperresponsiveness in corticosteroid-treated asthma. J Allergy Clin Immunol 2000; 105: 752-759.

32 Zanini A, Chetta A, Saetta M, et al. Chymase-positive mast cells play a role in the vascular component of airway remodeling in asthma. J Allergy Clin Immunol 2007; 120: 329-333.

33 van den Toorn LM, Prins J-B, de Jongste JC, et al. Benefit from anti-inflammatory treatment during clinical remission of atopic asthma. Respir Med 2005; 99: 779-787.

34 Bentley AM, Hamid Q, Robinson DS, et al. Prednisolone treatment in asthma. Reduction in the numbers of eosinophils, T cells, tryptase-only positive mast cells, and modulation of IL-4, IL-5, and interferon-gamma cytokine gene expression within the bronchial mucosa. Am J Resp Crit Care Med 1996; 153: 551-556.

35 Peters MC, Mekonnen ZK, Yuan S, et al. Measures of gene expression in sputum cells can identify TH2-high and TH2-low subtypes of asthma. J Allergy Clin Immunol 2014; 133: 388-394.

36 Terakawa M, Tomimori Y, Goto M, et al. Eosinophil migration induced by mast cell chymase is mediated by extracellular signal-regulated kinase pathway. Biochem Biophys Res Commun 2005; 332: 969-975.

37 Barnes PJ. Corticosteroid resistance in patients with asthma and chronic obstructive pulmonary disease. J Allergy Clin Immunol 2013; 131: 636-645. 